\title{
Transatlantica
}

Revue d'études américaines. American Studies Journal

\section{Maurice Couturier. Nabokov ou la cruauté du désir.} Seyssel : Champ Vallon, 2004. 365p. 26 Euros.

\section{René Alladaye}

\section{CpenEdition}

Journals

Édition électronique

URL : http://journals.openedition.org/transatlantica/862

DOI : $10.4000 /$ transatlantica.862

ISSN : $1765-2766$

Éditeur

AFEA

Référence électronique

René Alladaye, « Maurice Couturier. Nabokov ou la cruauté du désir. », Transatlantica [En ligne], 1 | 2005, mis en ligne le 22 avril 2006, consulté le 29 avril 2021. URL : http://journals.openedition.org/

transatlantica/862 ; DOI : https://doi.org/10.4000/transatlantica.862

Ce document a été généré automatiquement le 29 avril 2021

\section{(c) (i)}

Transatlantica - Revue d'études américaines est mis à disposition selon les termes de la licence Creative Commons Attribution - Pas d'Utilisation Commerciale - Pas de Modification 4.0 International. 


\title{
Maurice Couturier. Nabokov ou la cruauté du désir.
}

\author{
Seyssel : Champ Vallon, 2004. 365p. 26 Euros.
}

\section{René Alladaye}

1 La lecture peut avoir partie liée avec la transgression. Maurice Couturier en apporte la preuve dans son dernier ouvrage, Nabokov ou la cruauté du désir, en enfreignant l'un des plus célèbres interdits nabokoviens, celui de la lecture psychanalytique de son œuvre. On se souvient des préfaces des romans où l'auteur ne se fait jamais faute de décourager la moindre velléité freudienne et d'une réponse des plus tranchantes administrée dans le cadre d'un entretien: "Laissons les crédules et les vulgaires continuer à croire que toutes les infortunes mentales peuvent être guéries par une application quotidienne de vieux mythes grecs sur les parties intimes de leur individu » (Intransigeances).

2 Ce genre de déclaration aurait de quoi démoraliser plus d'un chercheur, mais Maurice Couturier, qui n'en est pas à son coup d'essai, ne se laisse pas facilement intimider. Geoffrey Green avait commencé de relever le défi en signant en 1988 un Freud and Nabokov déjà intéressant dans lequel il démontrait que ce rejet, comme souvent chez Nabokov, n'est pas simple car ces théories psychanalytiques qu'il prétendait répudier, il les connaissait en fait très bien et les utilisait. Nabokov ou la cruauté du désir pousse l'audace plus loin et lance une véritable exploration de l'œuvre de Nabokov sous l'angle psychanalytique. Soutenue, comme toujours chez Couturier, par une armature théorique extrêmement solide (Freud, Lacan, Anzieu, entre autres), l'analyse mène à une relecture dynamique des romans les plus connus (Lolita, Ada, Pale Fire) ou d'écrits moins fréquemment soumis à l'examen (le premier chapitre, par exemple, qui reprend dans le détail la question des rencontres textuelles entre certaines nouvelles et Autres Rivages, l'autobiographie, est passionnant).

3 Une relecture incisive aussi, parce qu'elle donne lieu à ouverture ou réouverture de débats. Maurice Couturier met en place une discussion critique de quelques approches récentes, la lecture métaphysique de Vladimir Alexandrov par exemple, tout en conservant une conscience aiguë des limites de sa propre entreprise et en insistant sur 
le fait que Nabokov est trop riche pour se laisser enfermer dans une grille de lecture unique, si sophistiquée soit-elle (131). Et ce n'est pas le moindre des mérites de l'ouvrage que de donner lieu lui-même à sa part de débat. Il est difficile à un nabokovien passionné de ne pas réagir à certaines assertions qui, pour être en cohérence totale avec l'argumentation dans laquelle elles s'insèrent, n'en paraissent pas moins l'inviter à saisir la balle au bond. Un exemple ? Dans le chapitre consacré à Lolita, Maurice Couturier s'attarde sur l'éveil sentimental et sexuel d'Humbert avec Annabel, et l'analyse ainsi : "Lors d'une autre rencontre, alors que les adolescents se préparent à franchir un nouveau pas dans leur intimité, deux intrus apparaissent: 'J'étais à genoux et sur le point de posséder ma bien-aimée quand deux baigneurs barbus, le vieil homme de la mer et son frère, sortirent des flots en nous criant des encouragements obscènes, et, quatre mois plus tard, elle mourut du typhus à Corfou' (35). Ici, le traumatisme n'est pas tant dû à ce que l'adolescent doive réprimer son éjaculation qu'au fait qu'il soit surpris par des adultes en train de copuler avec Annabel; ces encouragements paillards rabaissent l'acte sexuel à son niveau le plus vulgaire et transforment une scène délicieuse en un spectacle hideux aux yeux du garçon » (205-206). Si le commentaire est ici parfaitement en accord avec la perspective générale de l'ouvrage, je ne puis m'empêcher de penser que l'on perd une certaine part de la saveur du texte et de son jeu en ne voyant pas dans ce passage un exemple d'humour féroce typique de Nabokov. On sait à quel point il aimait à éreinter - autant sinon plus que Freud-certains écrivains dont il jugeait la production médiocre, et il me semble difficile de ne pas reconnaître dans ce vieil homme de la mer et son frère, tous deux barbus, une de ses cibles favorites, Hemingway, ici accompagné de l'un de ses plus illustres personnages. Il ne me parait guère surprenant qu'un auteur dont Nabokov ne manquait pas une occasion de dire la vulgarité littéraire (la fameuse notion de poshlust) soit convoqué pour transformer en scène scabreuse un épisode effectivement délicieux. Maurice Couturier a évidemment vu la plaisanterie, mais son choix délibéré de perspective l'incite à la laisser dans l'ombre.

Une décision discutable selon moi, mais qui ne fait que mettre en valeur le mérite - triple - du livre. Il permet de revisiter l'œuvre avec un guide érudit et plein de finesse; il engage les études nabokoviennes dans une voie encore peu défrichée; il incite au débat et fournit l'occasion d'une confrontation dynamique des lectures, dont le lecteur sort enthousiaste.

\section{INDEX}

Thèmes : Recensions

\section{AUTEUR}

RENÉ ALLADAYE

Université de Toulouse-le-Mirail 